\title{
Research on Public Welfare Poster Design Based on Cognitive Psychology — Taking the Poster Design for Wildlife Protection as an Example
}

\author{
${ }^{1}$ Wuhan Textile University, Wuhan, Hubei, China \\ *Corresponding author. Email: $382910331 @ q q . c o m$
}

Rui Chen ${ }^{1, *}$

\begin{abstract}
As a medium by which public opinion is spread, public welfare posters use the elements of visual symbols and words to reflect social problems, guide the public to examine, coordinate and solve problems and move public welfare programs in a positive direction with the unique artistic charm, rich connotation, distinctive themes and other relevant poster visual languages. However, whether the information conveyed by the poster can be effectively accepted by the public, so as to change their thoughts and actions, depends on the factors such as the visual expression method, the choice of subject and content, emotional appeal and psychological identity of the poster design. Based on several aspects of cognitive psychology, this paper studies public welfare posters for wildlife protection. This paper is composed of three parts: The first chapter gives a brief overview of public welfare posters, and then analyzes and studies the current situation of public welfare posters in China and abroad. The second chapter briefly describes cognitive psychology and discusses the influence of cognitive psychology on public welfare poster design. The third chapter, based on cognitive psychology, discusses the innovative way of public welfare poster design. First of all, it is necessary to understand the audience, choose the right design symbol elements, and strengthen the visual effect of the poster, so as to trigger the psychological recognition of the public, so that the social value and publicity function of the public welfare poster can be increased to the maximum. Through the research of this topic, the analysis of public welfare poster design from the perspective of cognitive psychology can provide designers with new design thinking and methods, so as to promote the development of public welfare poster design towards the direction of diversification.
\end{abstract}

Keywords: public welfare posters, cognitive psychology, social problems, diversification

\section{INTRODUCTION}

Nowadays, in the rapidly developing social environment, more and more social problems are exposed. As an important visual tool for information dissemination, posters of different types are aimed at different groups of people, with different publicity purposes and final expected effects. Public welfare posters for wildlife protection are one of the theme types of posters. They convey information to the public through their own visual language and arouse the public's concern and thinking about wildlife protection. From the perspective of cognitive psychology, rich symbolic elements should be used to attract the attention of the public, and the connotation and thought of wildlife protection should be transmitted to the public, and special expressions should be adopted for the public to remember and think. An excellent poster for wildlife protection can not only raise the public's awareness of animals, but also contribute to animal protection. The innovative design of wildlife protection posters from the perspective of cognitive psychology can better demonstrate the influence.

\section{A BRIEF INTRODUCTION OF PUBLIC WELFARE POSTER DESIGN}

\section{A. Overview of public welfare poster}

1) Concept of public welfare poster: The name "海 报" (海报, literally "sea sticker" in Chinese) of poster has a long history. According to legend, during the Qing Dynasty, foreigners transported goods from the sea to China's coastal docks to put up advertisements everywhere in order to promote the products they wanted to sell, so the local residents called them 海报. Poster is a kind of print advertisement with graphic, text, color, layout and other elements posted in public 
places. Posters are generally divided into social politics, public welfare, environmental protection, cultural activities and other types. The content is expressed in a visual form to attract the eye of the audience and arouse their thinking.

Public welfare poster is a kind of poster, which uses art form as a carrier to publicize and safeguard public interests. It mainly disseminates state decrees, social morality, environmental protection and traffic safety to the public. It reflects the ideology of the deep structure of human spirit, which includes values, world outlook, aesthetics and morality. With the help of public welfare posters, we can communicate with the audience spiritually, cultivate people's public awareness and guide their behavior habits, so as to promote the healthy and stable development of social public welfare undertakings. "Posters are symbols of human wisdom and culture," Shigeo Fukuda once said. [1] Public welfare posters are not only a kind of design art, but also a kind of cultural art. They spread and promote the spirit of the times with visual element symbols and subtly influence people, making viewers internalize and externalize the civilized spirit.

2) The development trend of public welfare posters: With the progress of society and the rapid development of economy, more and more public welfare posters are emerging. But they are less and less recognizable with all the same visual elements. For example, in the early anti-smoking public welfare poster (see "Fig. 1"), a forbidden symbol was painted on a cigarette, accompanied by concise text description, showing a straightforward graphic representation without any visual appeal. Now designers are innovating in the form, content and materials of posters (see "Fig. 2"). The cigarettes are compared to weapons, the consumption of which is the death of mankind. Although we all know that cigarettes are harmful to the body, explicit pictures and words cannot arouse people's awareness of quitting smoking. Only meaningful and novel posters can attract people's attention. Public welfare posters aim to show a profound cultural accumulation through a series of social public welfare events, to better show contemporary people's outlook on life, world outlook and values, and to make positive guidance to the new group behavior and regulate the daily behavior of the social group, so as to guide the new social dynamics. [2] With the continuous development of the society, there is still a great space for the future development of public welfare posters, which will arouse people's thinking, guide their behavior and promote the progress of the whole society.

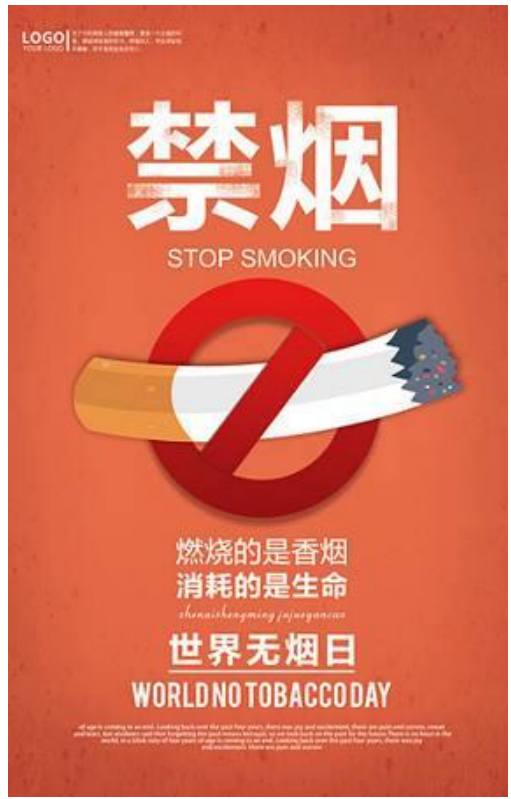

Fig. 1. "Stop Smoking".

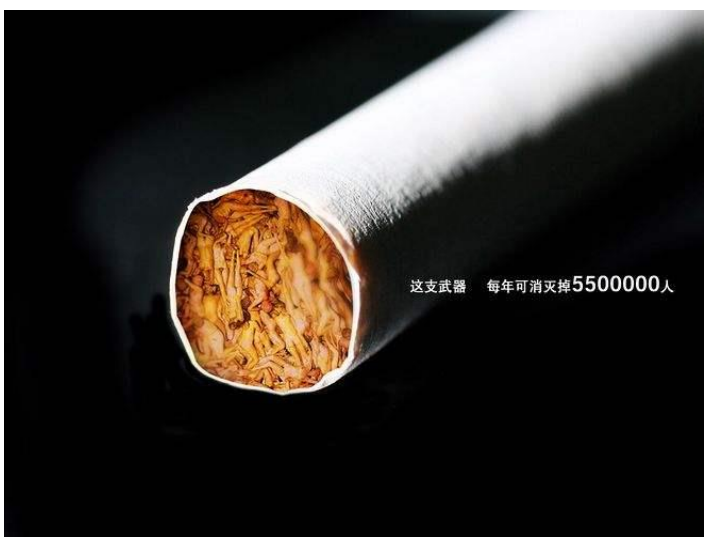

Fig. 2. "Stop Smoking" (Text: "This weapon kills 5500000 people a year").

\section{B. Analysis of the current situation of public welfare posters}

In the information age, public welfare posters are developing in a diversified direction, which promotes the continuous innovation of public welfare posters in content, form, material and technology, thus achieving breakthrough progress. The following is a detailed discussion and exploration based on the aspects of conciseness, humor and emotion in public welfare poster design in recent years.

1) Conciseness: The rapid development of social economy affects the development of poster design. To keep up with the times, poster design must take a simple route, with more simple and intuitive design 
thinking and way of element mining and information transmission. [3] Simple public welfare poster design can quickly guide the viewer's line of sight, understand the content of the work, and obtain the conveyed information. Even viewers with limited education can clearly understand the content and obtain information.

2) Humor: Humorous public welfare posters are designed by designers to express the theme through humorous and interesting images after understanding the theme, which are profound and thought-provoking. Public welfare posters adopt humorous and vivid visual images to guide people's behavior and promote social progress. At the same time, people can think and standardize their behavior when they see the posters.

3) Emotion: Public welfare posters proceed from the public interest, reflect social problems, arouse public sentiment, regulate public behavior and advocate social ethics. An excellent public welfare poster can convey the central idea to the public, and at the same time make people internalize the idea in the heart and externalize it in the practice. Only by moving people with emotion can the role of public welfare posters be fully played.

Since the 21st century, with the development of information age and science and technology, there are more innovations in the form style and content of design. In the field of public welfare posters, the innovative design of the content and form of the posters creates visual impact and resonates with the audience's psychology. Therefore, the world's public welfare poster design has been unprecedented development.

\section{A BRIEF INTRODUCTION TO COGNITIVE PSYCHOLOGY}

\section{A. Cognitive psychology}

1) The concept of cognitive psychology: Cognitive psychology is a psychological science emerging in the mid-1950s in the West. It mainly studies the high-level psychological process of human beings, and studies the information cognition mechanism and process that cannot be directly observed, including the information that mainly involves consciousness and perception, thinking, memory, attention, language cognition and learning, emotion and social cognition, reward and decision-making, etc. [4] Cognitive psychology regards human as an information processing system, and regards cognitive process as information processing process, including the encoding, storage and extraction of sensory input.

2) Development of cognitive psychology's influence on design: Every designer can encounter this situation, when the designer does not understand the viewer's behavior and thought process, a series of problems will occur. In fact, the fundamental starting point of design is people-oriented. In order to design good works, it is not only the ability of designers themselves that is important, but more importantly, designers should learn and understand the psychological activities of viewers. Cognitive psychology regards the human brain as a system for processing information, and human cognitive process is the process of information processing, and each component of the information processing system is related to each other in a certain way, not a single activity. Only by further understanding the viewer's psychological response, establishing a connection with the work, and resonating with it, can the efficiency of design be naturally improved and people's profound thinking on the theme of the work be aroused.

\section{B. Cognitive psychology and public welfare poster design}

1) Attention in cognitive psychology and public welfare poster design: In life, when hungry and thirsty, people tend to focus more on food and water and less on other things, which explains their selective attention. The choice of attention ensures that people can focus their attention on the important stimuli, exclude all the minor stimuli, and thus perceive and adapt to the external environment more effectively.

Attention is a filtering mechanism in information processing and a person's selective perception of environmental stimuli. [5] Just as when people come across acquaintances on the street, their perception naturally takes the acquaintance as the object of perception, while other people or things around them become part of the perceptual background and are automatically ignored. Nowadays, with the rapid development of society and the rapid spread of information, it is easy for people to get lost in the sea of all kinds of information. In fact, people can only pay attention for 10 minutes. So how do we capture the audience's attention to the poster in the limited time and in a sea of so much information? This requires us to use the selectivity of attention. If a person is concentrating on one thing, he will filter out other distractions.

In the design of public welfare posters, we can use the principle of attention in psychology to use strong color contrast, innovative material elements, novel layout and other visual effects to create a strong visual impact and thus leave a deep impression on the audience. Contemporary social life is characterized by a fast pace. If a poster is not innovative or novel, it is impossible for it to stand out in the ocean of information. If it fails to catch the public's attention and convey the main information to people, it will fail to give play to the value and significance of the poster. 
Only designing posters with strong visual impact can leave people a photographic impression, trigger their thinking and standardize their behavior. In the poster "Media Violence" (see "Fig. 3") designed by a student of Purdue University, a man holding a "weapon" made up of a camera and film shows that violence in media films and television can have a negative impact on the younger generation. The overall picture adopts black and red tones with strong contrast, novel visual elements and clear visual hierarchy. The concise picture, bright colors and unique elements show the theme incisively and vividly, attracting the audience's attention and thinking.

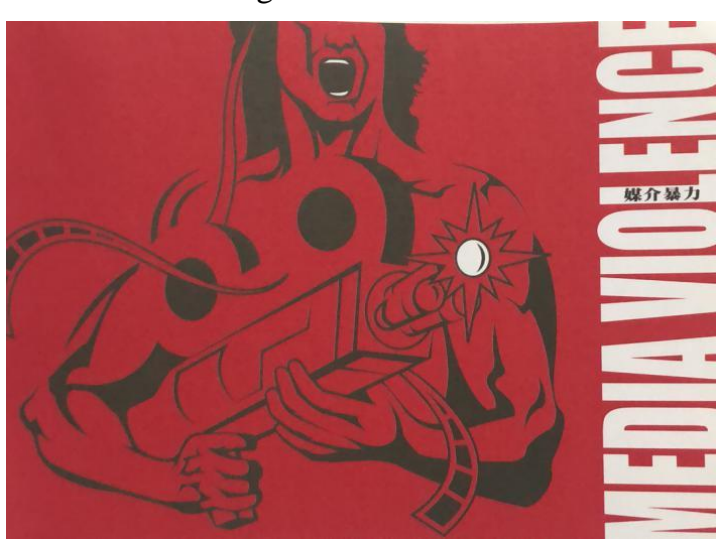

Fig. 3. "Media Violence".
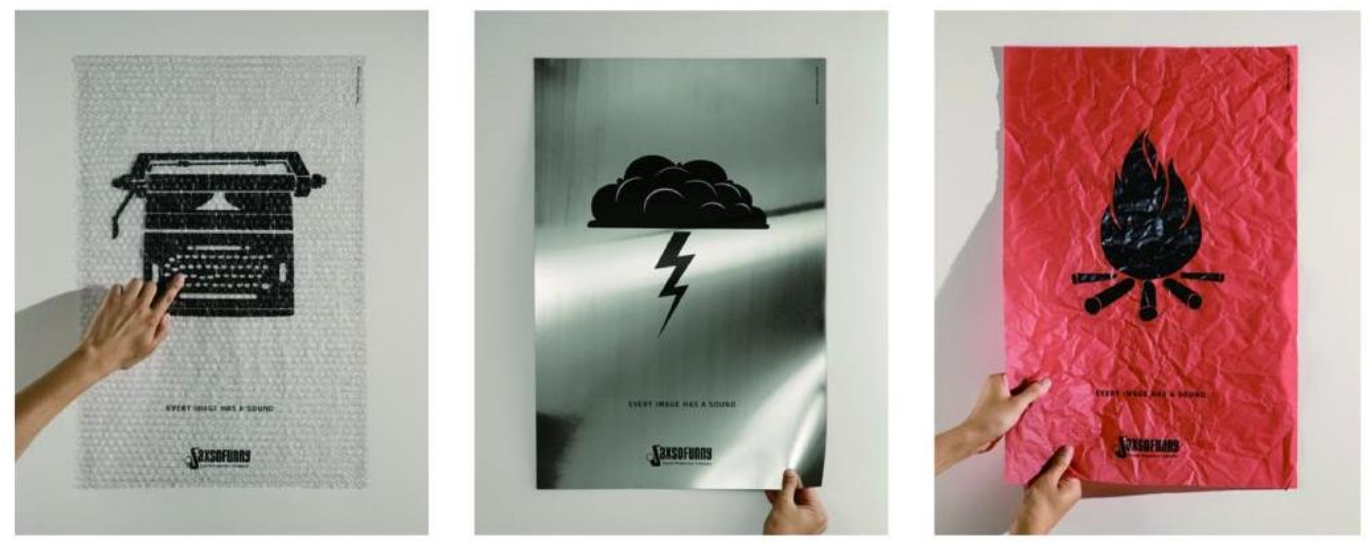

Fig. 4. Every Image has a Sound.

3) Memory and public welfare poster design in cognitive psychology: We've all been there: on the phone with someone, they ask us to contact someone right now and give the contact number, but instead of having a pen and paper by our side, we have to verbally repeat the number over and over again. However, we find that this method is unreliable for memory. This is because the information of memory is easy to be disturbed by external factors.
2) Synesthesia and public welfare poster design in cognitive psychology: We have five main sense organs: the ear, the eye, the nose, the tongue and the body, and correspondingly, we have five main senses: hearing, sight, smell, taste and touch. In fact, in our design practice, these five senses interconnect and interact with each other, which can be called synesthesia. Suppose that a pattern of dry feces is placed in an open space, which looks good from a distance. When we look closer, it turns out to be feces, and our psychology immediately gives a reaction of resistance and rejection. This is where the intellectuality comes into play.

In the current public welfare poster design, a good work should also take people's synesthesia psychology into consideration

Design is interlinked, connected. For example, a group of posters called "Every Image has a Sound" (see "Fig. 4") designed by Saxsofunny, an independent foreign designer and voice production company in Brazil, make people unconsciously have a strong interest in this group of posters through the sense of touch and hearing. When viewers see the works, they input the information into the brain for processing by visual, tactile and other senses, and then distinguish the likes and dislikes by perception. Therefore, in the design of public welfare posters, synesthesia in cognitive psychology can be flexibly applied to leave the audience an imprinted impression. 
in their brains. With so many things in life, not all things are worth remembering. Only those things that can arouse our thinking can be remembered. There is a group of posters "Animal Children" (see "Fig. 5" and "Fig. 6"), which inspire people to put themselves in animals' shoes. If the one being killed is your child, will you continue your behavior? This group of posters make use of people's psychology by comparing animals to children. When facing animals, they enlarge people's love for children, so as to achieve the purpose of protecting animals. Emotional resonance is also an important part of the viewer's memory of the poster.

Among the numerous public welfare posters, can we remember each one of them? Of course we can't. Nowadays, there are a large number of public welfare posters. In order to make our works stand out among them and be remembered by the audience and arouse their resonance and thinking, we must consider the audience's memory program when appreciating the posters, and design works should meet the requirements of memory structure.

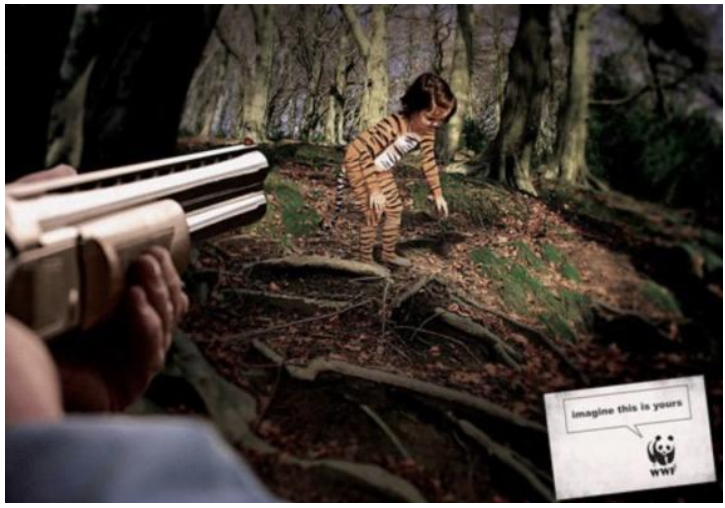

Fig. 5. "Animal Children".



Fig. 7. Series of public service advertisements for animal protection, WWF.

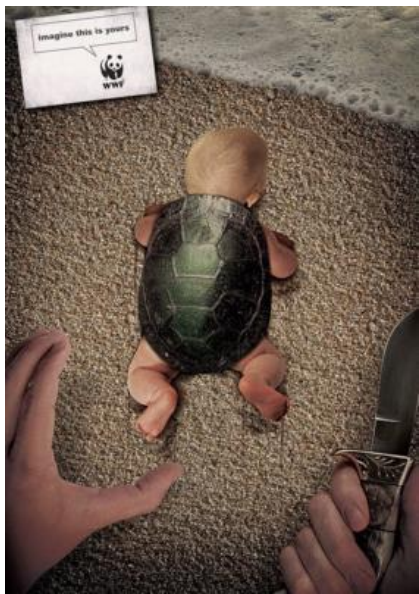

Fig. 6. "Animal Children".

\section{DESIGN OF PUBLIC WELFARE POSTER FOR WILDLIFE PROTECTION BASED ON COGNITIVE PSYCHOLOGY}

\section{A. Highlighting the poster theme based on the principle of attention in cognitive psychology}

From the principle of attention in cognitive psychology, it can be found that people do not pay attention to all the information in the numerous poster messages, but are selective in the process. Therefore, in today's fast-paced world, to keep the public's attention on the works, it is necessary to give the works distinct themes and enable the audience to quickly understand the inner meaning of the works. In the design of WWF's poster for wildlife protection, it can be found that they adopt overlapping forms. For example, in the "Fig. 7", the line drawings of handbags and clothes are put on the pictures of wild animals. The contrast is strong and the theme expresses clearly that people should not harm wild animals for the sake of material life. The reasonable design can reduce the wrong interpretation of the poster. The idea is clear, so that viewers can further understand and understand the message conveyed by the poster. 


\section{B. Comprehensive sensory factors based on the cognitive psychology of synesthesia principle}

By combining cognitive psychology with the principle of synesthesia, we can design not only visually, but also in other senses, such as touch, and combine various sensory factors. Taking "Fig. 7" for example, we can change the line drawings of handbags and clothes into fluffy materials, so as to highlight the authenticity of the picture and guide people to understand that there are a series of fresh lives behind the beautiful clothes. The innovation of threedimensional poster can allow the viewer have a new sensory experience, thus getting a deep impression on this work.

\section{Enhancing visual impact based on the memory principles in cognitive psychology}

Whether a poster can attract people's attention and memory mainly depends on its visual impact For the public welfare posters for wildlife protection, a connection can be established between the content and people's lives, so that people can recall the posters in their daily life after watching them. Poster design is not just about attracting people's attention, but more importantly, it is also about leaving an impression. That is, when the poster disappears in front of people's eyes, it can also recall the content of the poster, arouse people's thinking, and exert certain behavioral influence. In "Fig. 7", crocodiles and leopards are directly associated with clothing. Even after watching, people can remember this poster whenever they see fur clothes. Therefore, in the design of public welfare posters, it is necessary to use text information carefully, because too much useless information will cause visual fatigue of the audience. The image and text should be concise and comprehensive, highlight the theme information, and the useless text information should be filtered. The use of simple pictures can produce a strong visual impact, so that the public get a deep impression of the work.

\section{CONCLUSION}

Through the analysis of the research status of poster design in China and abroad, it's known that synesthesia, attention, memory, representation and other aspects in cognitive psychology play a very important role in people's viewing of poster works. People's cognition of something is the overall reflection influenced by both physical reality and people's psychological effect. In the process of visual recognition, psychological effect and external environmental factors will have a profound impact on the viewer's cognitive behavior. The fundamental starting point of modern design is centering on people. Therefore, the design target positioning and design realization of poster design should be discussed from the psychological and behavioral perspectives of the target audience. The posters express the thought content by visual language with the aid of plane visual symbols. At present, public welfare poster design pays more attention to the enhancement of attraction, appeal and innovation consciousness, and at the same time, it also strengthens the attention and understanding of social hot issues. So expression technique and form style of public welfare poster design should be consistent with the public's aesthetic demand and psychological demands. It is necessary to seize the psychological characteristics of the viewer by means touching emotional approaches, inspire them, and make them voluntarily accept the spirit connotation and values expressed by posters from inner consciousness, and practice them in life, so as to assume the public welfare publicity responsibility of such posters. With the rapid development of today's society, people's access to information is getting easier and easier, and designers have to pay more attention to the understanding and research of people's cognitive psychology on the basis of innovative content due to their quick attention and choice of things. Through the research and analysis of cognitive psychology, designers can design public welfare posters that touch the hearts of the public based on the memory, synesthesia, attention and representation in cognitive psychology, so as to improve the level and social value of social welfare poster design and design more excellent poster works.

\section{References}

[1] Da Zhixiang. Discussion on Public Welfare Poster Design [J]. Art and Design, 2009 (5): 31-33. (in Chinese)

[2] Wang Fanglin. Analysis of Modern Public Welfare Poster Design [J]. Education and Teaching Forum, 2017 (15): 94-95. (in Chinese)

[3] Wu Huatang. Discussion on the Role of Graphics in Poster Advertisement Design [J]. Science and Education, 2008(20): 265. (in Chinese)

[4] Liu Xun, Wu Yanhong, Li Xingshan. Cognitive Psychology: Foundations for Understanding the Brain, Mind, and Behavior [J]. Science \& Technology Review, 2011, 26 (6): 620-629. (in Chinese)

[5] LiuSha. Design Psychology [M]. Shanghai: Shanghai People's Fine Arts Publishing House, 2012, pp. 216. (in Chinese)

[6] Donald Norman. The Design of Everyday Things [M]. Mei Qiong Trans. Beijing: CITIC Press Group, 2003.

[7] Zhou Zhyu. Thought and Design [M]. Beijing: Peking University Press, 2016. (in Chinese)

[8] Zuo Mian, Xiong Ying, Yu Shuwei. Psychology for Design [M]. Hefei: Hefei University of Technology Publishing House, 2009. (in Chinese)

[9] Julia Chu. Poster Design [M]. Beijing: China Architecture \& Building Press, 2005. (in Chinese)

[10] Cao Yaoqin. Research on Public Welfare Poster Design Based on Cognitive Psychology [D]. Zhejiang: Hangzhou Normal University, 2015. (in Chinese) 